\title{
EMG Activity of Masseter Muscles in the Elderly According to Rheological Properties of Solid Food
}

\author{
Au Jin Kang, $\mathrm{MD}^{1}$, Don-Kyu Kim, $\mathrm{MD}^{1}$, Si Hyun Kang, $\mathrm{MD}^{1}$, \\ Kyung Mook Seo, MD ${ }^{1}$, Hyoung Su Park, PhD $^{2}$, Ki-Hwan Park, PhD ${ }^{2}$ \\ ${ }^{1}$ Department of Physical Medicine and Rehabilitation, Chung-Ang University College of Medicine, Seoul; \\ ${ }^{2}$ Department of Food Science \& Technology, Chung-Ang University, Seoul, Korea
}

Objective To assess the impact of aging on masticatory muscle function according to changes in hardness of solid food.

Methods Each of fifteen healthy elderly and young people were selected. Subjects were asked to consume cooked rice, which was processed using the guidelines of the Universal Design Foods concept for elderly people (Japan Care Food Conference 2012). The properties of each cooked rice were categorized as grade 1, 2, 3 and $4\left(5 \times 10^{3}\right.$, $2 \times 10^{4}, 5 \times 10^{4}$, and $5 \times 10^{5} \mathrm{~N} / \mathrm{m}^{2}$ ) respectively. Surface electromyography (sEMG) was used to measure masseter activity from food ingestion to swallowing of test foods. The raw data was normalized by the ratio of sEMG activity to maximal voluntary contraction and compared among subjects. The data was divided according to each sequence of mastication and then calculated within the parameters of EMG activities.

Results Intraoral tongue pressure was significantly higher in the young than in the elderly $(\mathrm{p}<0.05)$. Maximal value of average amplitude of the sequence in whole mastication showed significant positive correlation with hardness of food in both young and elderly groups $(\mathrm{p}<0.05)$. In a comparisons between groups, the maximal value of average amplitude of the sequence in whole mastication and peak amplitude in whole mastication showed that mastication in the elderly requires a higher percentage of maximal muscle activity than in the young, even with soft foods $(\mathrm{p}<0.05)$.

Conclusion sEMG data of the masseter can provide valuable information to aid in the selection of foods according to hardness for the elderly. The results also support the necessity of specialized food preparation or products for the elderly.

Keywords Mastication, Deglutition disorders, Aged persons, Food hardness, Surface electromyography

Departments of Physical Medicine and Rehabilitation, Chung-Ang University Hospital, Chung-Ang University College of Medicine, 102 Heukseok-ro, Dongjak-gu, Seoul 06973, Korea. Tel: +82-2-6299-1881, Fax: +82-2-6298-1866, E-mail: donkim21@cau.ac.kr

() This is an open-access article distributed under the terms of the Creative Commons Attribution Non-Commercial License (http://creativecommons.org/ licenses/by-nc/4.0) which permits unrestricted noncommercial use, distribution, and reproduction in any medium, provided the original work is properly cited. Copyright $\odot 2016$ by Korean Academy of Rehabilitation Medicine 


\section{INTRODUCTION}

Recent demographics show that Korea is turning into an aging society [1]. As the proportion of the elderly increases, problems related to aging are becoming important social issues. Difficulties in health problem are common for the elderly. Some problems affect quality of life, although some of them are not definitely categorized as "diseases". Dysfunction in mastication is one of them $[2,3]$. Moreover, masticatory dysfunction not only affects quality of life, but also promotes swallowing difficulty and undernutrition, and further, results in severe illness such as aspiration pneumonia $[4,5]$. Many factors can affect masticatory function and cause symptoms associated with the condition. For example, difficulty of mastication may result from the loss of teeth or the use of dentures. In addition, changes in neural control or masticatory muscle function may also contribute to masticatory dysfunction in the elderly population. In addition, the mechanical properties of food can be associated with difficulties in eating in the elderly [6]. In Japan, which is a rapidly aging society like Korea, masticatory problems of the elderly are an important concern and as a result special food products have been developed for this population. The Japan Care Food Conference has established the Universal Design Foods (UDF) concept, which classifies food into four categories according to hardness (Table 1). The foods are categorized by their texture in consideration with how easy they are to masticate.

In these days, variable devices and methods have been introduced to objectively evaluate masticatory muscle function during mastication. However, some methods have limitations within this study design. For example, chewed food particle size analysis and color-changing chewing gum are methodological options to evaluate the masticatory efficiency. However, chewed food particle size analysis is only suitable for hard, crushable food and regular spherical food particles [7-9]. Color-changing chewing gum is limited in that it is not a true food product, which is what we aim to investigate; furthermore, it is no longer available due to safety concerns $[10,11]$. On the other hand, surface electromyography (sEMG) for masticatory muscles is non-invasive, non-painful, and applicable to various types of test foods, including sticky foods $[12,13]$.

We designed this study to assess the effects of aging on masticatory muscle function with the use of sEMG according to the hardness changes of cooked rice. The basic concept of this study is that changes in oral physiology in the elderly, especially muscle strength as well as neural control, can be a significant factor in masticatory discomfort. Hence, masticatory muscle activity in elderly people may behave differently according to changes in food hardness when compared with that in young people.

\section{MATERIALS AND METHODS}

\section{Subjects}

Starting in May 2013, 15 elderly and 15 young people who had no significant masticatory dysfunction and did not have other significant past medical history which might affect the function of mastication or swallowing were recruited for the study. The two groups were the young adult group $(\mathrm{n}=15 ; 1$ male and 14 female; mean age, 26.56 \pm 3.21 years $)$ and the elderly group $(n=15 ; 2$ male and 13 female; mean age, $76.65 \pm 3.48$ years). The

Table 1. The Univeral Design Foods guidelines for elderly people

\begin{tabular}{|c|c|c|c|c|}
\hline & Stage 1 & Stage 2 & Stage 3 & Stage 4 \\
\hline Classifications & Able to chew easily & $\begin{array}{l}\text { Able to smash with } \\
\text { gums }\end{array}$ & $\begin{array}{l}\text { Able to smash with } \\
\text { tongue }\end{array}$ & $\begin{array}{l}\text { Able to swallow without } \\
\text { chewing }\end{array}$ \\
\hline $\begin{array}{l}\text { Standards of } \\
\text { chewing }\end{array}$ & $\begin{array}{l}\text { Contains hard and big } \\
\text { ingredients, a little } \\
\text { hard to swallow }\end{array}$ & $\begin{array}{l}\text { Contains hard and big } \\
\text { ingredients not easy to } \\
\text { swallow }\end{array}$ & $\begin{array}{l}\text { Contains soft and small } \\
\text { ingredients, easy to } \\
\text { swallow }\end{array}$ & $\begin{array}{l}\text { Hard to swallow if } \\
\text { contains solid food }\end{array}$ \\
\hline $\begin{array}{r}\text { Standards of } \\
\text { swallowing }\end{array}$ & $\begin{array}{l}\text { Able to swallow } \\
\text { commonly }\end{array}$ & $\begin{array}{l}\text { Depends on } \\
\text { ingredients, } \\
\text { hard to swallow }\end{array}$ & $\begin{array}{l}\text { Have experience hard } \\
\text { to swallow water or } \\
\text { liquid ingredients }\end{array}$ & $\begin{array}{l}\text { Hard to swallow water } \\
\text { or liquid ingredients }\end{array}$ \\
\hline Hardness $\left(\mathrm{N} / \mathrm{m}^{2}\right)$ & $5 \times 10^{5}$ & $5 \times 10^{4}$ & $2 \times 10^{4}$ & $5 \times 10^{3}$ \\
\hline
\end{tabular}

Cited from the Japan Care Food Conference 2012 (http://www.udf.jp/about_udf/section_01.html). 
young group was recruited via public postings in and around the Chung-Ang University School of Medicine campus. The elderly group was recruited in senior citizen centers in Dongjak-gu, Seoul, Korea via invitation to join the study. Exclusion criteria included a history of neurological disease, less than 25 teeth, and presence of periodontal disease, which can influence masticatory function. While recruiting subjects, exclusions were administered by trained interviewers using questionnaires and intraoral examination. Written informed consent was obtained from all subjects to assess mastication through sEMG. The Chung-Ang University Hospital Institutional Review Board approved this study.

\section{Methods}

To compare masticatory muscle activity among subjects, sEMG activity of the maximal voluntary contraction (MVC) of masticatory muscles were measured first. MVC data were obtained from biting a tendon of meat as hard as possible three times. The electrodes of an 8-channel sEMG device (Laxtha, Daejeon, Korea) were attached at the midpoint of the belly of both masseter muscles and the reference electrode was attached at the wrist. After MVC assessment, intraoral tongue pressure of all participants was measured using the Iowa Oral Performance Instrument (IOPI Medical, Redmond, WA, USA). Participants were asked to keep an intraoral air-filled balloon probe between the tongue and hard palate, and to push the balloon toward the hard palate as forcefully as possible. Between the triplicate measurements, brief rests were offered to reduce fatigability.
As the staple foods of Asians, cooked rice was selected for this study and processed to UDF guidelines to evaluate masticatory muscle function during mastication with graded changes in hardness. Prior to the evaluation of masseter muscle activity during mastication, 3 cycles of chewing practice for each test food were implemented. In the upright-seated position, subjects were asked to eat the test foods prepared for this study. Cooked rice (CJ Hetbahn; CJ CheilJedang Corp., Seoul, Korea) was processed to a graded hardness under the guidance of the UDF concept for elderly people (Japan Care Food Conference 2012). The properties of each food were categorized as stage 1 (thin gruel, $5 \times 10^{3} \mathrm{~N} / \mathrm{m}^{2}$ hardness), stage 2 (gruel, $2 \times 10^{4} \mathrm{~N} / \mathrm{m}^{2}$ ), stage 3 (soft-boiled, $5 \times 10^{4} \mathrm{~N} / \mathrm{m}^{2}$ ), and stage 4 (boiled, $5 \times 10^{5} \mathrm{~N} / \mathrm{m}^{2}$ ); 8 grams of each food was provided (Fig. 1). Hardness properties of each food sample were measured using a texture analyzer (Stable Micro Systems, Godalming, Surrey, UK) with a 50-kg load cell. Starting at the point of food ingestion, sEMG data was recorded until the participant swallowed the bolus of food; videofluoroscopy swallowing study was used as a guide to ensure the completion of the swallowing sequence. During sEMG data measurement, pre-conditioning data settings included frequency filtering within $50-50,000$ $\mathrm{Hz}$ using power spectrum analysis then absolute valuing and raw data curve smoothing with Gaussian filters. After mastication of each test food was complete, participants were asked to rest for 3 minutes to minimize muscle fatigue. Fig. 2 is an example of a masticatory muscle sEMG recording. All of the data were divided according to each sequence of mastication and then calculated to 'mean of
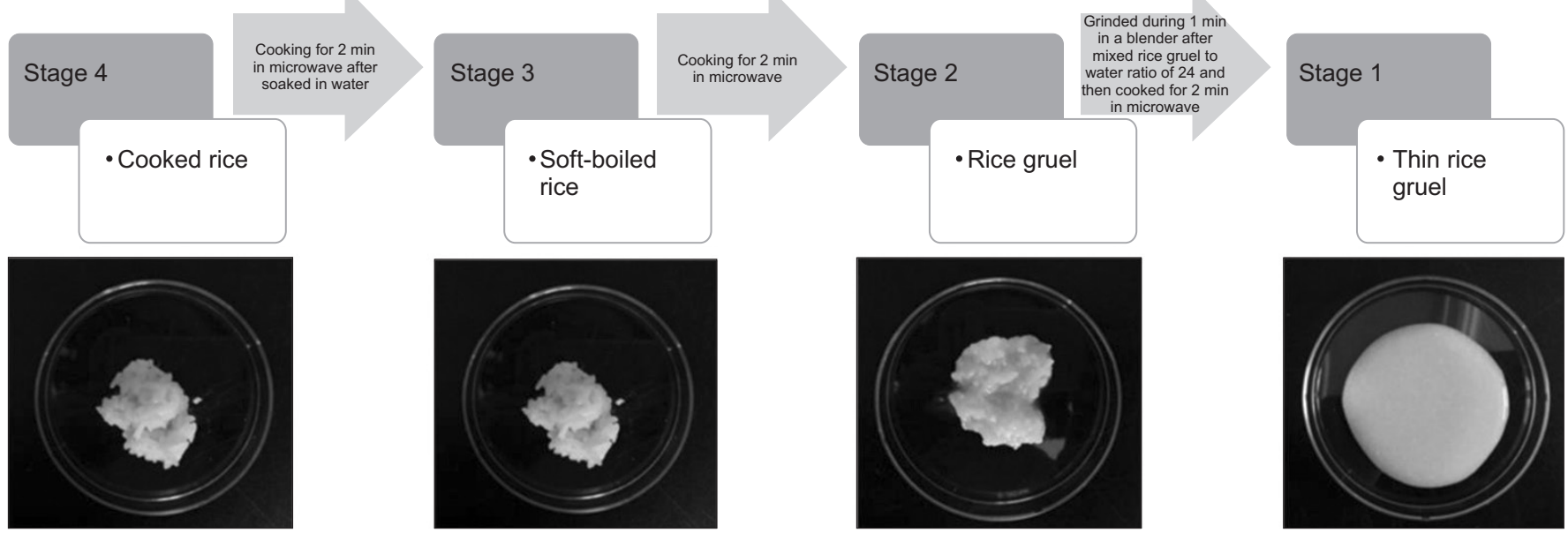

Fig. 1. Test food samples according to the Universal Design Foods guidelines. 

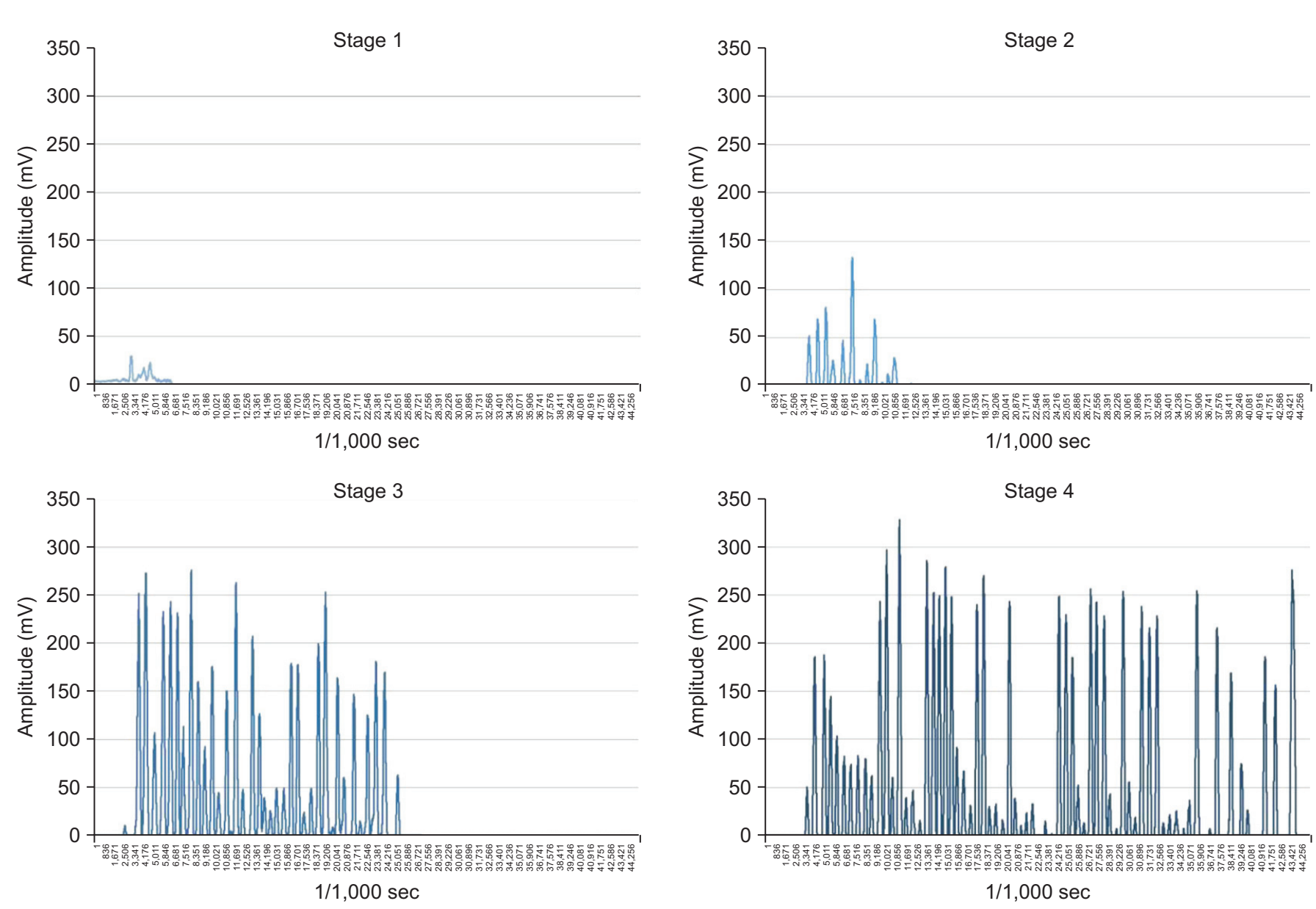

Fig. 2. Examples of surface electromyography activity according to hardness changes of test foods.

average EMG activity of each sequence (mV),' 'maximal average amplitude of the sequence in whole mastication $(\mathrm{mV})$,' 'mean of peak amplitude of each sequence $(\mathrm{mV})$,' 'peak amplitude in whole mastication ( $\mathrm{mV})$ ' as sEMG amplitude parameters, 'integral activity of amplitude during whole mastication $(\mathrm{mV} / \mathrm{s})$ ' as a representation of work factor(s), 'total numbers of masticatory sequence' and 'whole masticatory duration (s)' (Fig. 3). To ensure comparability among subjects, the raw data was normalized by the ratio of each sEMG activity recording to MVC activity. The normalizing process was conducted using individual MVCs of subjects, and the MVC data was divided and calculated using the same method as a purposed analyzing parameter (raw data calculated from each parameter / MVC calculated from the purposed parameter, i.e., raw measured peak amplitude / peak amplitude of isometric MVC). Statistical analysis was performed using the SPSS package ver. 17 for Windows (SPSS Inc., Chicago, IL, USA). One-way ANOVA was used to compare sEMG activity among changes in food hardness. Post-hoc tests were conducted using the Duncan correction method. Comparisons between the young and the elderly were performed with the Mann-Whitney test. Significance was defined by a p-value less than 0.05 .

\section{RESULTS}

All 30 subjects completed the experiments without any adverse responses.

\section{Comparison of tongue strength and SEMG activity of MVC}

In IOPI measurement, the young group $(64.67 \pm 10.59$ $\mathrm{N} / \mathrm{m}^{2}$ ) showed higher tongue pressure than the elderly group $\left(33.83 \pm 16.59 \mathrm{~N} / \mathrm{m}^{2}\right)$, and the difference was statistically significant $(\mathrm{p}<0.05)$. In the comparison of raw data of MVC, although there was no significance, MVC amplitude of the young group $(102.51 \pm 52.06 \mathrm{mV})$ was higher than that of the old group $(72.09 \pm 45.76 \mathrm{mV})$. Table 2 shows 

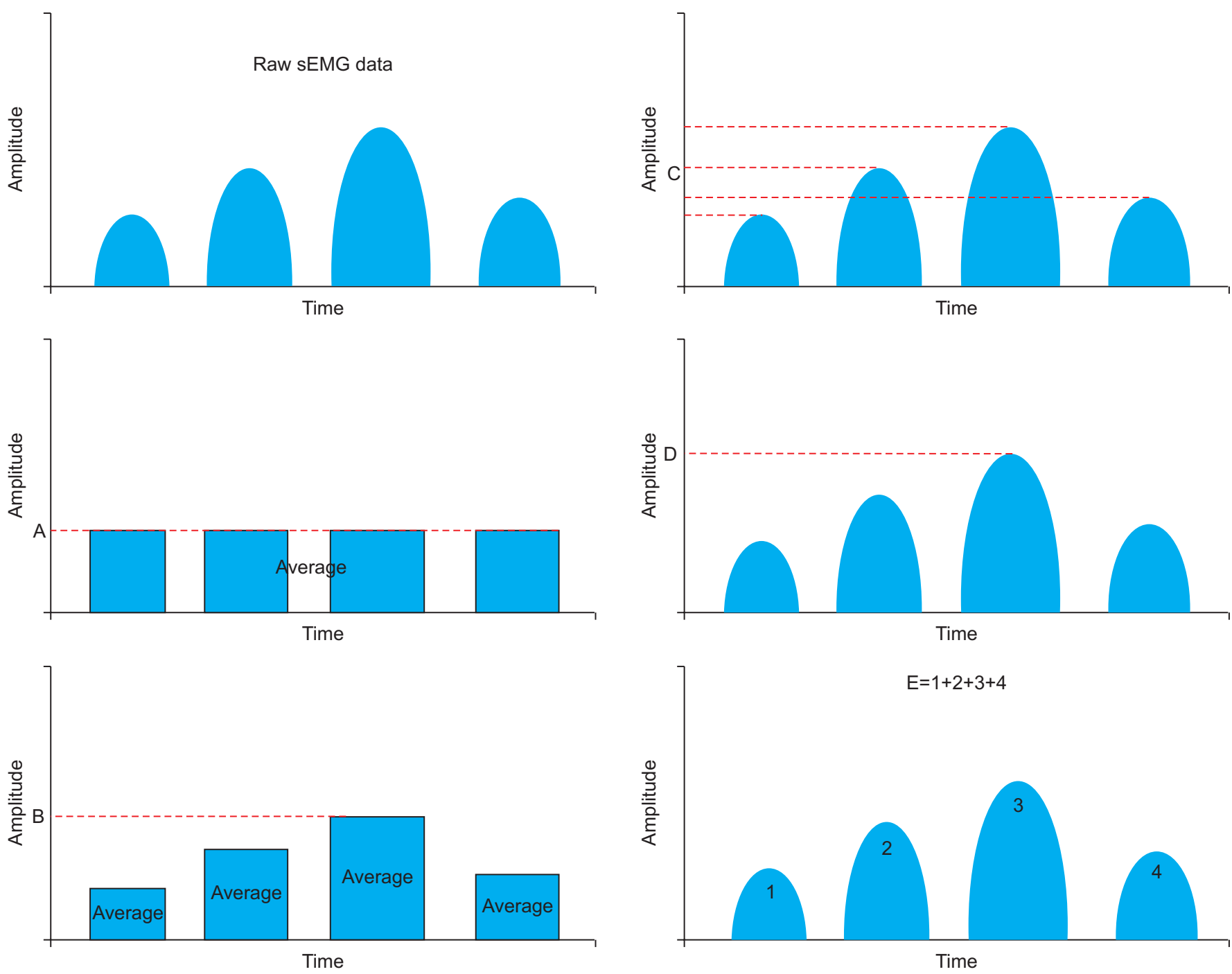

Fig. 3. Simplified diagrams of surface electromyography (sEMG)-analyzing parameters. 'A' mean of average EMG activity of each sequence, 'B' maximal average amplitude of the sequence in whole mastication, 'C' mean of peak amplitude of each sequence, ' $\mathrm{D}$ ' peak amplitude in whole mastication, and ' $\mathrm{E}$ ' integral activity of amplitude during whole mastication.

Table 2. Demographics of participants and comparisons of MVC and IOPI between groups

\begin{tabular}{lcc}
\hline & Young group & Old group \\
\hline Age $(\mathrm{yr})$ & $26.56 \pm 3.21^{*}$ & $76.65 \pm 3.48^{*}$ \\
\hline Gender (male:female) & $1: 14$ & $2: 13$ \\
\hline Number of teeth & $30.22 \pm 3.19$ & $28.11 \pm 1.54$ \\
\hline MVC $(\mathrm{mV})$ & $102.51 \pm 52.06$ & $72.09 \pm 45.76$ \\
\hline IOPI $\left(\mathrm{N} / \mathrm{m}^{2}\right)$ & $64.67 \pm 10.59^{*}$ & $33.83 \pm 16.59^{*}$ \\
\hline
\end{tabular}

Values are presented as mean \pm standard deviation or number.

MVC, maximal voluntary contraction; IOPI, Iowa Oral Performance Instrument.

${ }^{*} \mathrm{p}<0.05$, comparisons between the groups were conducted via independent t-test. comparisons of MVC and IOPI measurements.

Comparison of raw and normalized EMG activity among hardness changes in test foods

Upon analysis of raw sEMG data, analyzed values were increased according to the hardness increment of the test foods. There were statistical significant findings in some parameters. The 'integral activity of amplitude during whole mastication $(\mathrm{mV} / \mathrm{s})$ ' which represented the work of mastication showed a positive correlation with food hardness (the young group: $21.06 \pm 17.07,176.12 \pm 223.34$, $222.11 \pm 168.85,423.95 \pm 534.78 \mathrm{mV} / \mathrm{s}, \mathrm{R}^{2}=0.951$; the elderly group: $41.85 \pm 48.62,67.52 \pm 73.75,306.92 \pm 289.96$, 

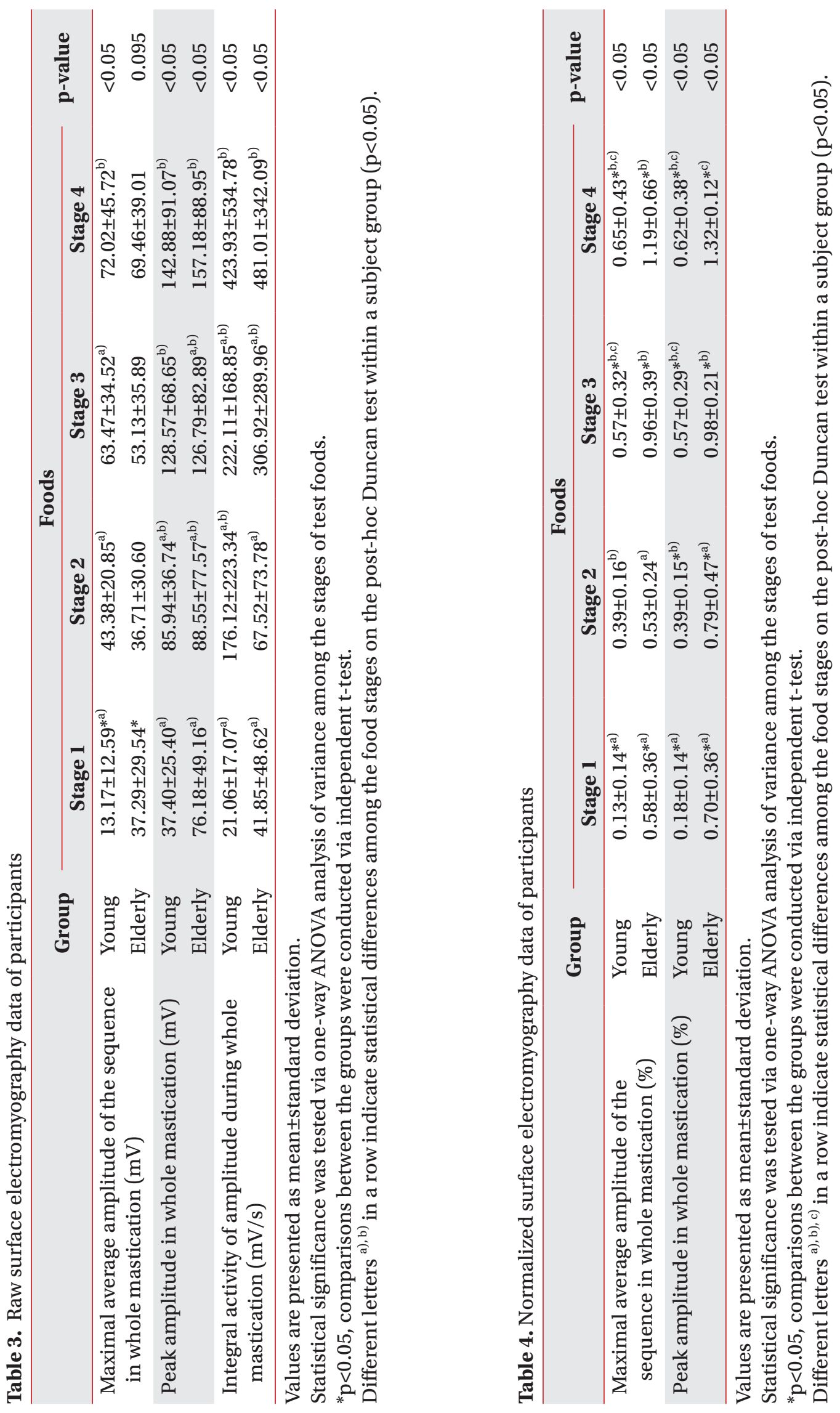
$\left.481.01 \pm 342.09 \mathrm{mV} / \mathrm{s}, \mathrm{R}^{2}=0.928\right)$, and these values were statistically significant $(\mathrm{p}<0.05)$ (Table 3$)$.

After normalization via MVC from each subject, there were more distinguishable differences according to hardness of food tested that were also statistically significant (Table 4). Normalized 'maximal value of average amplitude of sequences in whole mastication' was positively correlated with hardness changes of cooked rice in both groups (the young group: $0.13 \% \pm 0.14 \%$, $0.39 \% \pm 0.16 \%, 0.57 \% \pm 0.32 \%, 0.65 \% \pm 0.43 \%, \mathrm{R}^{2}=0.8556$; the elderly group: $0.58 \% \pm 0.36 \%, 0.53 \% \pm 0.24 \%, 0.96 \% \pm 0.39 \%$, $\left.1.19 \% \pm 0.66 \%, \mathrm{R}^{2}=0.9483\right)$ and these values were statistically significant $(\mathrm{p}<0.05)$. In addition, as the hardness of test foods increased, the frequency and duration of EMG activity of the masseter muscles also increased in both groups. Number of masticatory sequences (the young group: $3.67 \pm 2.96,17.56 \pm 11.68,35.67 \pm 14.27,45.22 \pm 20.77$, $\mathrm{R}^{2}=0.9875$; the elderly group: $8.22 \pm 6.69,14.57 \pm 8.06$, $32.29 \pm 16.95,45.00 \pm 15.47, \mathrm{R}^{2}=0.9618$ ) and 'whole mastication duration' (the young group: $9.37 \pm 2.15,15.83 \pm 6.91$, $29.89 \pm 9.64,36.55 \pm 12.58 \mathrm{~ms}, \mathrm{R}^{2}=0.9805$; the elderly group: $16.92 \pm 9.54,16.71 \pm 5.99,31.34 \pm 11.09,40.11 \pm 11.09 \mathrm{~ms}$, $\mathrm{R}^{2}=0.8033$ ) also showed the same tendencies in both groups according to changes in hardness of test foods, and these values were statistically significant $(\mathrm{p}<0.05)$ (Table 5).

\section{Comparisons between the young and the elderly}

In the comparisons of the young and the elderly, normalized 'maximal value of average amplitude of the sequence in whole mastication' showed that each stage of mastication in the elderly group requires a higher percentage of muscle activity than in the young group. This tendency was significant in stages 1,3 , and $4(p<0.05)$.
In addition, the analysis of normalized 'peak amplitude in whole mastication' (the young group: $0.18 \pm 0.14$, $0.39 \pm 0.15,0.57 \pm 0.29,0.62 \pm 0.38$; the elderly group; $0.70 \pm 0.36,0.79 \pm 0.47,0.98 \pm 0.21,1.32 \pm 1.12$ ) showed that mastication of each food type in the elderly requires a higher percentage of muscle activity than the young group for all stages of test foods, and these values were statistically significant (stages $1,2,3$, and 4$)(p<0.05)$. There were no significant differences in the normalized 'integral activity of amplitude during whole mastication'. The normalized comparison data between the groups are showed in Table 4. Comparisons of 'whole masticatory duration' and 'number of masticatory sequences' between the groups were not statistically significant.

\section{DISCUSSION}

From this study, we found that the elderly use a higher percentage of their own masticatory muscle reservoir than the young to masticate food of the consistency, and some parameters of sEMG can be a useful tool for evaluating masseter muscle function according to the hardness of foods.

In the raw data analysis, 'integral activity of amplitude during whole mastication' represented the work required for each of the test foods. There was a positive correlation with the hardness changes of the test foods (Table 3 ), but no statistical differences between the elderly and the young. Though the data showed a large standard deviation, it implies that the total work for pre-swallowing mastication depends not on the age of the group, but rather on foods hardness.

Although 'integral activity of amplitude during whole mastication' showed positive tendencies according

Table 5. Time parameters of mastication in each group

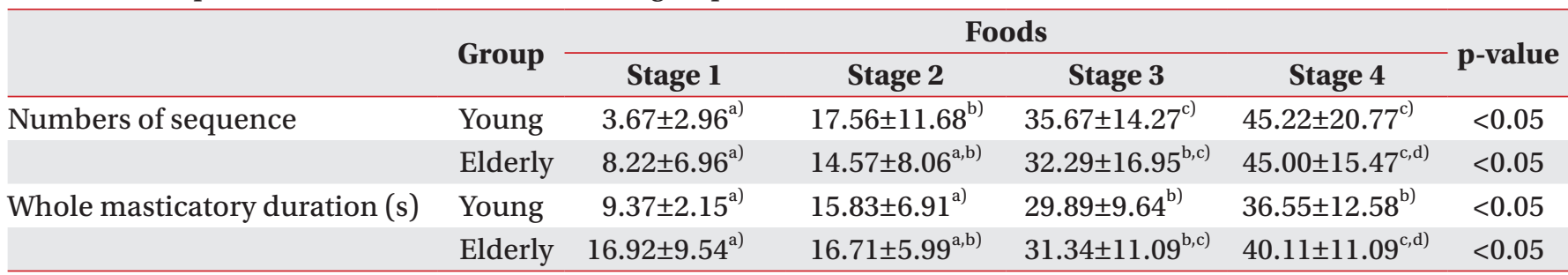

Values are presented as mean \pm standard deviation.

Statistical significance was tested via one-way ANOVA analysis of variance among the stages of test foods.

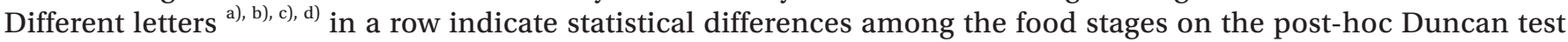
within a subject group $(\mathrm{p}<0.05)$. 
to hardness, most other parameters of sEMG raw data analysis showed a few statistical differences with large standard deviation. These results suggest that person to person variation of chewing patterns and maximal masticatory strength were too large to compare using raw data. Comparisons of sEMG data of MVC among the participants were not statistically significant, either. Quite a few past studies have shown that sEMG data without normalization has statistically significant differences when comparison was performed between and within the groups [14-16]. Furthermore, the importance of normalization in the interpretation of sEMG is well established from other previous studies. Comparison between the groups and within the group were conducted via a ratio of personal masticatory sEMG activity to MVC, because we found few statistical differences in masticatory sEMG activity directly for each test food, and this conversion meant the percentage of usage of personal own maximal bite force [17-19]. After normalization using MVC of each subject, EMG activity showed clearer statistical differences in comparisons within and between the groups.

In the comparison of hardness changes of test foods, 'maximal value of average amplitude of the sequence in whole mastication' showed positive correlation in accordance with food hardness and it was significant. From aforementioned study by Kohyama et al. [20], mean voltage, maximal voltage, muscle activity $(\mathrm{mV} / \mathrm{s}$, 'integral activity of amplitude during whole mastication' in this study) per chew and total muscle activity showed significance in the comparison of food hardness, however, in this study, normalized 'maximal value of average amplitude of the sequence in whole mastication' was significant according to the hardness of test foods. Each of the maximal values and averaged values alone are presumed to not represent the total masticatory characteristics according to hardness changes of test foods. The results demonstrate that electromyography activity of masseter muscles correlates with hardness of food and certain parameters of sEMG activity of masseter muscles can be chosen to assess masticatory muscle activity. Plus, sEMG parameters, especially 'maximal value of average amplitude of the sequence in whole mastication, could be used as tools to evaluate masticatory muscle function in clinical research. Furthermore, the processed foods showed differentiated masticatory muscle activity according to the UDF guidelines; the stages in the guidelines can be considered meaningful grading and a good reference to set appropriate standards for Koreans.

From the results of comparison between the young and the elderly groups with 'maximal average amplitude of the sequence in whole mastication' and 'peak amplitude in whole mastication', the proportion of masseter muscle activity to MVC was higher (in the elderly) than that of the young group with the same hardness stage of foods. It shows that the elderly require a higher percentage of chewing force ratio than the young. Even in the mastication of soft foods, the elderly used higher reservoirs of maximal mastication capability. However, whole mastication duration time and number of sequences were not statistically significant though the young group mastication time was shorter and had fewer sequences with soft food (Table 4). We can assume that though the elderly use a larger reservoir of masticatory strength, if they had sound dentition, they could chew food of certain hardness grades without any difficulty. Another reason we thought for the result was the elderly people swallowed food boluses that were incompletely masticated. In a previous study, the elderly showed incomplete bolus preparation with large food particle size before swallowing [21]. In this consideration, because the elderly use a large proportion of their masticatory reservoir in same time frame inefficiently, we can also assume that masticatory muscles of the elderly might be fatigued easily.

To estimate general oral and swallowing muscle strength, we measured intraoral tongue pressure. Intraoral tongue pressure measurement is one of methods to estimate chewing force because it is closely correlated with masticatory function [22-24]. The elderly group showed significantly lower IOPI measurements than that of the young group. These results show that the elderly might have lower intraoral muscle strength than the young group and furthermore, the results can imply bite force characteristics of the elderly group.

All of these results suggest the need for specialized food preparation or products for the elderly; EMG data of masseter muscles can give valuable information about selecting certain hardness stages of foods for the elderly.

There are some limitations to this study. During the raw data analysis, there were large standard deviations in the comparison within the groups and between the groups. We noted positive correlation with the stages of test foods, but the outcomes were not statistically significant. 
These results come from not only personal variation such as chewing habits and muscle strength, but also small subject numbers. The results showed significance only after normalization using MVC. If the sample size was larger, the raw data might show some tendencies which differ from this study representing the age effect.

There are many rheological factors that affect the masticatory process. For example, viscosity, adhesiveness of food and saliva production are such factors. In this study, because we want to identify the effect of food properties focused on hardness, there were limitations in control of food properties other than the hardness. Viscosity and adhesiveness of the bolus correlate with water content of processed foods, and saliva flow rate during mastication. These factors might alter the overall masticatory process, such as number of sequences and whole masticatory duration $[16,20]$. Further study for other types of test foods with control of hardness and other rheological properties as well as correlating rate of saliva flow measurement are needed.

\section{CONFLICT OF INTEREST}

No potential conflict of interest relevant to this article was reported.

\section{ACKNOWLEDGMENTS}

This research was supported by iPET (Korea Institute of Planning and Evaluation for Technology in Food, Agriculture, Forestry and Fisheries), Ministry of Agriculture, Food and Rural Affairs.

\section{REFERENCES}

1. Choi SJ. The family and ageing in Korea: a new concern and challenge. Ageing Soc 1996;16:1-25.

2. Locker D, Slade G. Oral health and the quality of life among older adults: the oral health impact profile. J Can Dent Assoc 1993;59:830-3, 837-8, 844.

3. Miura H, Miura K, Mizugai H, Arai $Y$, Umenai T, Isogai E. Chewing ability and quality of life among the elderly residing in a rural community in Japan. J Oral Rehabil 2000;27:731-4.

4. Ikebe K, Hazeyama T, Morii K, Matsuda K, Maeda Y, Nokubi T. Impact of masticatory performance on oral health-related quality of life for elderly Japanese. Int J Prosthodont 2007;20:478-85.

5. Martin BJ, Corlew MM, Wood H, Olson D, Golopol LA, Wingo $\mathrm{M}$, et al. The association of swallowing dysfunction and aspiration pneumonia. Dysphagia 1994; 9:1-6.

6. Mioche L, Bourdiol P, Peyron MA. Influence of age on mastication: effects on eating behaviour. Nutr Res Rev 2004;17:43-54.

7. Peyron MA, Mishellany A, Woda A. Particle size distribution of food boluses after mastication of six natural foods. J Dent Res 2004;83:578-82.

8. Mowlana F, Heath MR, Van der Bilt A, Van der Glas HW. Assessment of chewing efficiency: a comparison of particle size distribution determined using optical scanning and sieving of almonds. J Oral Rehabil 1994; 21:545-51.

9. Lucas PW, Luke DA, Voon FC, Chew CL, Ow R. Food breakdown patterns produced by human subjects possessing artificial and natural teeth. J Oral Rehabil 1986;13:205-14.

10. Ishikawa Y, Watanabe I, Hayakawa I, Minakuchi S, Uchida T. Evaluations of masticatory performance of complete denture wearers using color-changeable chewing gum and other evaluating methods. J Med Dent Sci 2007;54:65-70.

11. Tanimoto Y, Watanabe M, Kono R, Hirota C, Takasaki K, Kono K. Utility of color-changeable chewing gum to evaluate masticatory ability in communitydwelling elderly persons. Nihon Koshu Eisei Zasshi 2009;56:383-90.

12. Ferrario VF, Sforza C, Zanotti G, Tartaglia GM. Maximal bite forces in healthy young adults as predicted by surface electromyography. J Dent 2004;32:451-7.

13. Ferrario VF, Sforza C, Colombo A, Ciusa V. An electromyographic investigation of masticatory muscles symmetry in normo-occlusion subjects. J Oral Rehabil 2000;27:33-40.

14. Kohyama K, Mioche L. Chewing behavior observed at different stages of mastication for six foods, studied by electromyography and jaw kinematics in young and elderly subjects. J Texture Stud 2004;35:395-414.

15. Kohyama K, Mioche L, Martin JF. Chewing patterns of various texture foods studied by electromyography in young and elderly populations. J Texture Stud 2002;33:269-83. 
16. Peyron MA, Blanc O, Lund JP, Woda A. Influence of age on adaptability of human mastication. J Neurophysiol 2004;92:773-9.

17. Lehman GJ, McGill SM. The importance of normalization in the interpretation of surface electromyography: a proof of principle. J Manipulative Physiol Ther 1999;22:444-6.

18. Yang JF, Winter DA. Electromyographic amplitude normalization methods: improving their sensitivity as diagnostic tools in gait analysis. Arch Phys Med Rehabil 1984;65:517-21.

19. Ekstrom RA, Soderberg GL, Donatelli RA. Normalization procedures using maximum voluntary isometric contractions for the serratus anterior and trapezius muscles during surface EMG analysis. J Electromyogr Kinesiol 2005;15:418-28.

20. Kohyama K, Yamaguchi M, Kobori C, Nakayama Y, Hayakawa F, Sasaki T. Mastication effort estimated by electromyography for cooked rice of differing water content. Biosci Biotechnol Biochem 2005;69:1669-76.

21. Feldman RS, Kapur KK, Alman JE, Chauncey HH. Aging and mastication: changes in performance and in the swallowing threshold with natural dentition. J Am Geriatr Soc 1980;28:97-103.

22. Ono T, Iwata H, Hori K, Tamine K, Kondoh J, Hamanaka S, et al. Evaluation of tongue-, jaw-, and swallowing-related muscle coordination during voluntarily triggered swallowing. Int J Prosthodont 2009;22:493-8.

23. Hori K, Ono T, Nokubi T. Coordination of tongue pressure and jaw movement in mastication. J Dent Res 2006;85:187-91.

24. Clark HM, Henson PA, Barber WD, Stierwalt JA, Sherrill M. Relationships among subjective and objective measures of tongue strength and oral phase swallowing impairments. Am J Speech Lang Pathol 2003;12:40-50. 